\title{
Method and design for economic operation of the pipeline based on the digital pulp index analysis
}

\author{
Chunlei Pan ${ }^{1, a}$, DianJun WANG ${ }^{2, b}$, Guangyue $\mathrm{Pu}^{1, \mathrm{c}}$, Xueyong Wang ${ }^{1, \mathrm{~d}}$ \\ ${ }^{1}$ Yunnan Da Hongshan Pipeline Co., Ltd., Kunming, 650504, China \\ ${ }^{2}$ Faculty of Information Engineering and Automation, Kunming University of Science and \\ Technology, Kunming, 650500, China \\ a491941203@qq.com, bwdj0011@163.com, ${ }^{\mathrm{c}}$ steelkm@foxmail.com, ${ }^{\mathrm{d}} \mathrm{km}$ _trans@foxmail.com
}

Keywords: Digital; Solid-liquid two-phase flow; Economy; Index Analysis

\begin{abstract}
In view of the present economic operation index data control is insufficient, lack of effective analysis and calculation method, and the unity of the information release platform. In this paper, the solid-liquid two-phase slurry pipeline transmission performance indicators related to economic factors and the means were analyzed for relevant indicators of iron ore pipeline Dahongshan economic operation were analyzed and Dahongshan iron ore concentrate pipeline as an example method to protect digital pipeline economy. In the actual production run proved that the index analysis method has higher accuracy and reliability, to meet the needs of economic performance indicators analyzed digitized slurry pipeline transportation.
\end{abstract}

\section{Introduction}

Dahongshan iron ore pipeline began in Xinping County of Yuxi City, Yunnan Province Gasa town Dahongshan iron ore, after more than 170 kilometers of long distance slurry pipeline to suppress sent to Kunming Steel, pathways eleven townships in four countries, the elevation drop km iron ore pipeline for the length of the country first. Dahongshan pipeline companies in the development process in the past few years, it has already established a number of information platform, but each time information platform only to business needs and establish associated with the lack of effective integration between the various platforms, resulting in the current isolated operation of various systems, information systems, decentralized and not unified, the lack of unified planning of the situation, so that timely and effective business management is not able to view the production and operation of various departments. To solve the above problems of the pipeline company, the concept of digital pipeline was born. "Digital pipeline" of new ideas, that make full use of geographical information technology, database technology, aerospace remote sensing technology, three-dimensional simulation technology, "Digital Earth" core technology, to carry out the pipeline covering the whole life cycle, the whole process of the "digital pipeline" technology system research and engineering application practices [1]. Applications include digital pipeline is dynamic cost analysis, including many relatively independent digital technology integration, digital integrated service platform is a set of pipeline space, networked, intelligent and visualized as an integrated technology systems.

Fine iron pipe manufacturing operations for the process, to ensure the safe operation of the premise for lower operating costs, it may create higher economic returns, but also in order to maintain sustainable development of enterprises. Therefore, a good iron concentrate slurry pipeline transmission pulp economic performance indicators of management is particularly important.

\section{Economic indicators data content}

Economic performance indicators for the concentrate pipeline composed of iron Dahongshan view, divided into three main components:

(1) B level indicators: B grade index is mainly aimed at enterprise leadership set, micro economic indicators, the analysis of enterprise production control plays an important role and 
reference. Such as: economic growth, the value of the net assets profit margin, profit improvement rate.

(2) C level indicators: C grade index is mainly aimed at enterprise each department supervisor and setting, production of every department plays an important role in guidance and adjustment. Such as yield, cost and power consumption.

(3) Refining indicators: Also known as equipment assessment indicators, showing the production process specific equipment maintenance data, the production process conditions and circumstances play an important role in guiding role adjustment. Such as the number of unplanned maintenance, equipment monthly maintenance plan execution rate and monthly equipment downtime accident rate.

Details of the economic performance indicators, as shown in Table.1.

Table.1 Economic performance indicators list

\begin{tabular}{|c|c|c|c|}
\hline & B level indicators & $\begin{array}{c}\text { C level } \\
\text { indicators }\end{array}$ & Refining indicators \\
\hline of detail & Economic increase & production & Unplanned maintenance times \\
\hline & Net profit margin & Cost & $\begin{array}{c}\text { Spare material consumption } \\
\text { indicators }\end{array}$ \\
\hline & Profit improvement rate & Energy & $\begin{array}{c}\text { Device monthly maintenance } \\
\text { plan execution rate }\end{array}$ \\
\hline & Cost reduction rate & & Effective send mine rate \\
\hline & $\begin{array}{c}\text { Per capital profitability } \\
\text { Reduce energy }\end{array}$ & & Equipment intact rate \\
\hline & $\begin{array}{c}\text { consumption rate of the } \\
\text { yuan output value }\end{array}$ & & \\
\hline
\end{tabular}

\section{System work-flow analysis}

\section{System functions}

(1) Production data management. Digital pipeline system by the various departments of the head office of economic value added, net assets profit margin, profit improvement rate, cost reduction rate, yield and all branches per capita profitability, cost and power consumption and other operating parameters, sub-sector category management, accumulation of production data [2].

(2) Economic indicators and economic operation. On-line monitoring data for the dynamic calculation, quantitative economic indicators, and the formation of economic growth, net profit margin and profit increasing rate, cost reduction rate, create profit and ten thousand yuan output value per capita energy consumption to reduce the rate of economic indicators such as trend analysis diagram [3].

(3) Operation management. Based on the production data, dynamic calculation results, affecting the safe and economic operation condition of real-time analysis, make condition adjustment judgment. The normal operation of the production process tracking.

(4) Maintenance optimization. Through detailed indicators of production couldn't solve the safe and economic problems in the operation of the data is stored, for the following comprehensive repair records provide insufficient information. 
(5) Economic dispatch. Provide digital dispatching piping system of each department in the trend analysis indexes of economic operation, to facilitate reasonable scheduling.

\section{System Flow}

Explained platform for digital pipeline Limited Yunnan Dahongshan:

(1) The online monitoring data and the production index data entry system inherent contrast differences between platforms. Platform system all data stored in the database, the database is the foundation of the system data processing, real-time collection of data and calculation results should be stored in the database. The system for real-time requirements are not very high, the amount of data is not large, does not require a massive database, it uses a relational data SQL Server 2008. Database has Class B indicators report, C-level indicators report, detailed indicators report. System configuration information table is the most basic data table, which is stored in the acquisition of the measured data point labels, and other system parameters from a SIS interface information systems [4].

(2) Statistical differences through the system platform data obtained, together with the economic indicators calculated on the operating mode to control economic indicators. And economic indexes of operation data timely feedback to system platform. Digital pipeline system economic operation index analysis flow chart is shown in figure.1.

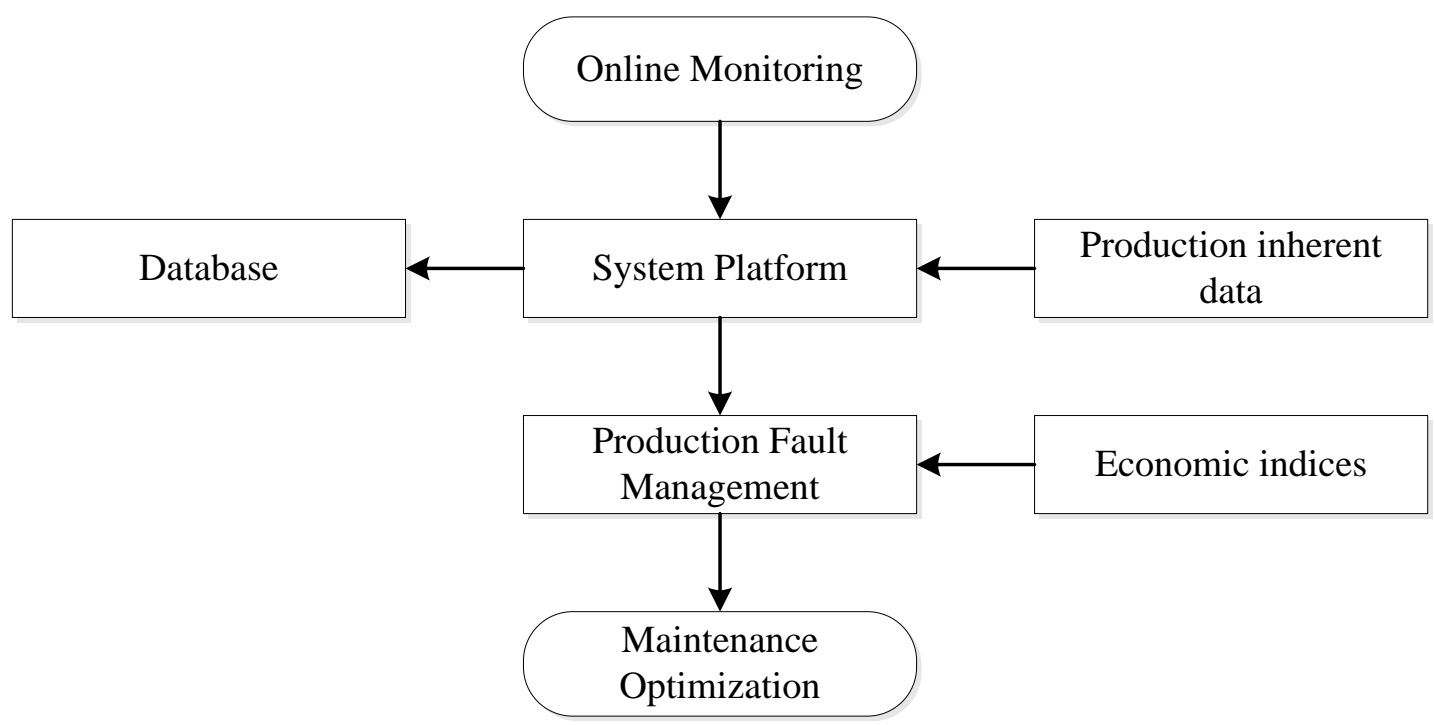

Fig.1. Index of economic operation flowchart

(3) By trend analysis and statistical data, manage the production failure, timely maintenance optimization, production process and the data back to the system platform. Digital pipeline system flow chart shown in figure.2 equipment evaluation indexes.

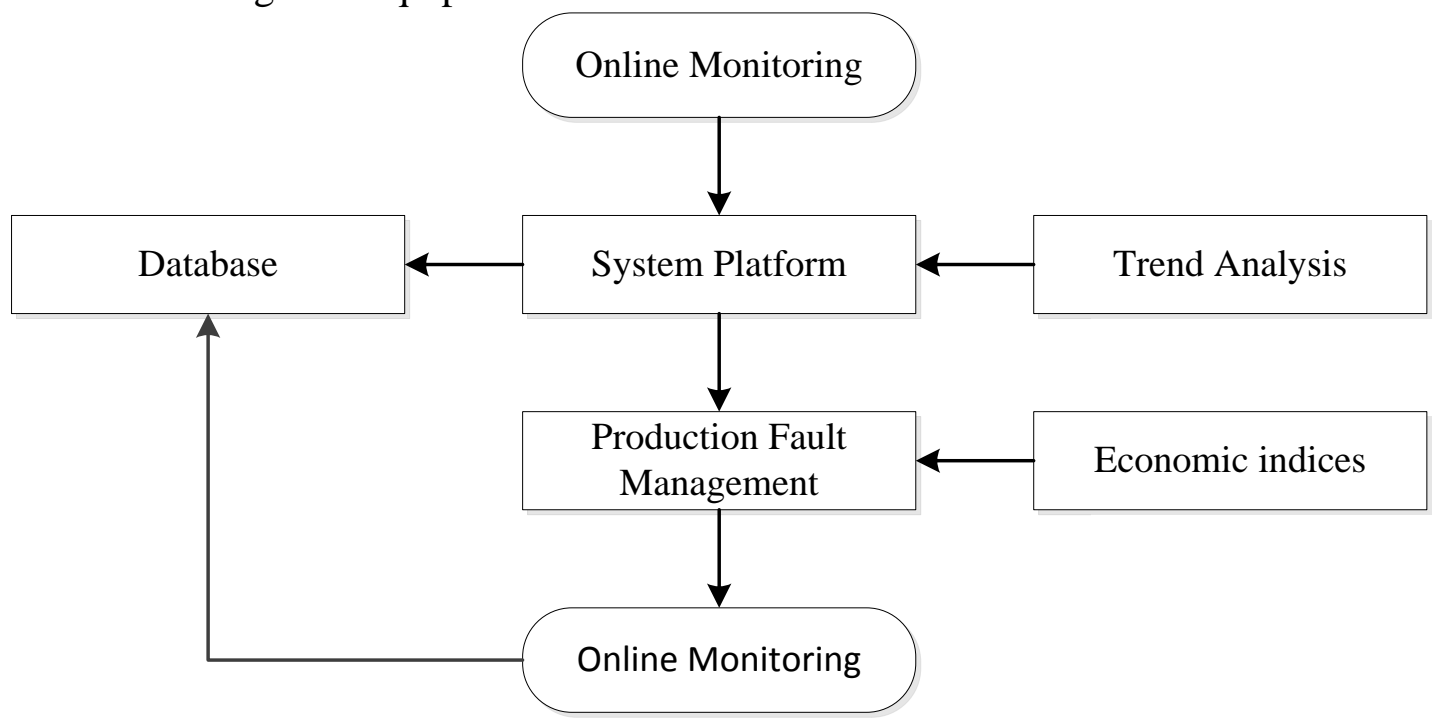

Fig.2. Equipment assessment indicators flowchart 


\section{Summary}

Indicators of economic operation is not only the work target digital pipeline system must be established, but also digital pipeline system open source throttling, drop the core content of consumption; More digital pipeline system make the production plan, judge the important basis of the management level.

\section{Acknowledgement}

This work is supported by National Natural Science Foundation of China (No. 51169007), Science \& Research Program of Yunnan province (No.2011CI017 \& 2012CA022\&2013DH034).

\section{References}

[1] WANG Rui-ping,TAN Zhi-qiang,et all. Technique Research and Development Summarization of “Digital Pipeline”[J], Geomatics \& Spatial Information Technology, 2011, 34(1).1-9.

[2] LI Bin. Study on economic operation and reasonable dispatching[J]. NORTH CHINA ELECTRIC POWER, 1999, (8).14-17.

[3] YIN Mao-cong. Economic and technical indicators Thermal Power Plant Management and Discussion[J]. MANAGEMENT \& TECHNOLOGY OF SME, 2010, (3).4.

[4] SHI Yong, CUI Huan-sun,et all. Economic Index and Examination Management System of Large Thermal Power Plant[J]. Electric Power Science and Engineering, 2008, 24(10).53-56. 